\title{
TÜRK DÜNYASI HALK EDEBIYYATINDA OBA İNANCI
}

\author{
THE BELIEF OF NOMADIC TENT IN THE FOLK LITERATURE OF THE \\ TURKIC WORLD
}

Rövşen ALİZADE*

ÖZ: Bu makalede Oba inancının Türk dünyası halkları arasındaki adlandırılışı ve tanımlanmasına dair sorunsal hususlar ele alınıp incelenmiș, söz konusu inancın Türk halklarının halk edebiyatı alanındaki yeri ve önemi hakkında değerlendirmeler yapılmıştır. "Oba"nın dilbilimsel açıdan arz ettiği işlevselliğin aslında semiyotik gösterge bütünü gibi ortaya çıktığına değinilmiş, bu olgunun bazı ses bilgisel özelliklerinin mekân veya yerle ilgili olduğu kanısı üzerinde de durulmuştur. Mekân veya yer kavramlarının vatan unsurunun oluşmasındaki etkisi ve bu etkinin sonucu olarak söz konusu unsurun Oğuz eposuna yansıması meselesine açıklık getirilmiştir. Oba tabirinin şecere, topluluk, taş yığını, toprak, kurgan, mezar taşı, çadır vs. anlamları kapsadı̆̆ kaydedilmiş, bu tabirin vatan olgusunun kutsallık kazanmasında önemli etken gibi yer aldığı ve vatan olgusunun doğrudan ilk mitolojik birimlerle ilintili olduğu vurgulanmıștır.

Türk dünyası mitolojik düşüncesi kapsamında ele alınıp incelenen Oba inancının ilgili olduğu mitsel kavram veya anlayıșların ișlevselliği belirtilmiș, bazı mitolojik karakterlerin ise "oba"dan kopan olgularla irtibatından söz edilmiştir. Türk halkları arasında gerçekleșen ayin ve merasimlerin çeșitliliğinden bahsedilmiș ve bu hususta "Kitab-i Dede Korkut" eposundan verilen örneklerle öne sürülen fikirler desteklenmiștir. Ayin ve merasimlerin oyun niteliğinde olduğuna dikkat çekilmiş, bu tür oyunların sınırsızlığı hakkında araștırmacı tespitleri alıntı olarak verilmiştir. Ayrıca oba kültüyle eşleştirilebilen "otağ" ve "çadır" olgularının Oğuz eposunda bir ev niteliğinde geçtiği ve mitik dünya modelini sembolize ettiği kanıtlanmıștır. Gökyüzüyle çadır arasındaki ilişki hususunda Hakas Türklerinin inanç sisteminden bazı örnekler verilmiş ve Oğuz eposunda yer alan bir söylevdeki mitik dünya modeline yönelik ritüel hakkında net yorumlar yapılmıştır.

Anahtar Kelimeler: Oba, tabir, mitologem, dünya modeli, Oğuz eposu.

ABSTRACT: This article attempts to examine critical issues regarding naming and definition of nomadic tent belief among the peoples of Turkic World and assesses the said belief's place and significance in the folk literature of the Turkic peoples. It was mentioned that the functionality of "Nomadic Tent" from the linguistic perspective, in fact emerged as an integrity of semiotic indication; and it was emphasized that some phonetic characteristics of this phenomena are related to space and place. It was made clear that the effect of space and place notions on the mythological aspect of motherland and the reflection of the mythological aspects of motherland concept on the epic of Oghuz as the outcome of this effect. It was recorded that the concept of Nomadic Tent covers meanings of genealogy, community, rubble, soil, cairn, tombstone, tent, etc. and that this phenomenon has taken place as a significant factor in motherland concept's gaining holiness and it was underlined that the phenomenon of motherland is directly related to the mythological units .

* Dr. Öğretim Üyesi - İstanbul Aydın Üniversitesi Fen-Edebiyat Fakültesi Türk Dili ve

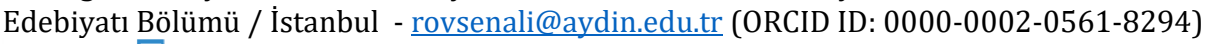


The article stated the functionality of mythological concepts and insights with which the belief of Nomadic Tent is related within the scope of the mythological though of the Turkic World, on the other hand some other mythological characters' connection with the facts that broke off from the "nomadic tent". The varieties of rituals and ceremonies among the Turkic peoples were mentioned and the arguments were supported with the samples extracted from the Dede Korkut Epic ("Kitab-i Dede Korkut"). The article draw attention to the fact that these rituals and ceremonies are like plays, and the researchers' findings regarding the infinity of such plays are provided as quotations. Furthermore, pavillion ("otağ") and tent ("çadır") concepts matched with nomadic tent cult are mentioned in the Oghuz epic as a characteristic of a house and it was proved that it symbolized the model of mythical world. Some sample have been provided from the belief systems of Hakas Turks regarding the matters between the sky and the tent, and clear comments are given on rituals of mythical world model in the Oghuz epic.

Keywords: Nomadic tents, interpretation, mythological aspects, world model, epic of Oghuz.

\section{Giriş}

Türk halklarının inanç dünyasındaki $O b a$ inancının ve bu inancı tanımlayan Ovoo, Oboo, Obon, Opa, Saloba, Çalama gibi tabirlerin Türk topluluklarının mitik görüşleriyle sıkı bir şekilde ilişkili olduğu bilinmektedir. $\mathrm{Bu}$ yazımızda ele alıp inceleyeceğimiz veriler, Türk mitik düşüncesiyle ilgili kelime ve deyimlerin ilkel katmanını belirlemek için ciddi ipuçları vermekten ziyade Türk dünyası halk edebiyatı alanındaki mitsel düşüncenin temel noktalarını tespit etmek ve bu düşüncenin geçtiği aşamaları gözlemleme hususunda da etkin olacaktır.

Görülmektedir ki, Türk halklarının mitsel ve dinsel inanç sistemini araştıranlar, pek çok zorluklarla yüz yüze kalmışlardır. Şöyle ki, Türk halklarının kendine özgü görüşleri, onlara yeni anlamlar veren yabancı mit ve dinlerle farklı dönemlerde karşılaşmış (bazen bu karşılaşmalar birbirini reddetmiş, bazen kaynaşmalarla sonuçlanmış), birbirinin içinde dağılarak birleşmiş ve Kam-şaman olgusundan Lamaizm ve İslam dinine kadar uzun bir mesafe kat etmiştir. İşte söz konusu çizgiyi dikkate alan araştırmacılar, çok eski devirlerde Çin'de ortaya çıkan ve zaman zaman Türk halkları arasında da yaygınlaşan görüşlere ve dini tarikatların etkisine de önem vermişlerdir. Türk halklarının boy reisleri veya bilge kişileri ise, dışarıdan gelen bu tür olgular karşısında Türk fikir dünyasının kapılarını hemen aralamamış, istişareler sonucunda bu "yenilikler"i yeniden biçimlendirmiş ve özgün kılmışlardır. Bu açıdan rahatlıkla söylemek mümkündür ki, dış etkenler, Türk sözlü gelenek ve göreneğini, özellikle de mitolojik düşüncenin özgülüğünü katiyen bozamamıştır.

\section{Oba İnancının Türk Halkları Arasındaki Adlandırılışı ve Tanımlanması Üzerine}

Oba inancının anlambilimsel açıdan yorumu, oluşumu, geçmiş olduğu tarihsel aşamalar ve Türk mitolojisindeki yeri üzerine yapılan araştırmalar, aslında yüzeysel araștırmalar niteliğindedir. Başta Mahmut Kaşgarlı olmakla 
birlikte James George Frazer, Matija Murko, Vasili İvanoviç Verbitskiy, Vera Pavlovna Dyakonova, Abdülkadir İnan, Mirali Seyidov ve diğer araştırmacılar, bu meseleye az veya çok derecede değinmişlerdir. Çağdaş Türkiye Türkçesinde "Oba" tabirinin ifade ettiği anlama dikkat ettiğimizde, "Türkçe Sözlük”te şu şekilde bir tarif yapıldığı görülmektedir: "Göçebelerin konak yeri; bu konak yerinde konaklayan göçebe halk veya aile; genellikle bölmeli göçebe çadırı" (Eren vd., 1988: 1097). "Oba" tabirinin çağdaş Azerbaycan Türkçesinde yer ve insan topluluğu anlamında kullanıldığını söyleyen Mirali Seyidov, bu tabirin eski deyimlere yansıması üzerine örnek dahi vermektedir: "Oba göçtü, yurdu kaldı" (Seyidov, 1994: 152). Seyidov'un Azerbaycan sahası Oba inancına dair tanımı ise net olarak şöyledir: “Azerbaycan'daki "oba” inancı XX. yüzyılın 30’lu yıllarına kadar yaşamıștır. Ancak bu inanç, yeterince araştırılmamıştır. Oba, Azerbaycan Türkçesinde söz, terim niteliğinde bugün de kullanılır. Birtakım deyimler, "oba" inancının Azerbaycan'da vaktiyle mevcut olduğunu kanıtlayabilir. Bu deyimler "oba" inancının Azerbaycan değerler düzenindeki yerini onarmak için de imkan tanır. Halk deyimlerinden biri şöyledir: "Oba yok, dede yok, obabaşını isterim". Bu deyimde geçen kelimeleri anlamsal açıdan sıralamış olursak, o zaman böyle anlaşılır ki, inançlı kişi, insana yardım eden "oba"yı değil, ecdadı temsil eden dedeyi değil, obabaşını, yani baş obanı, obanın başında bulunanı-Tanrıyı ister. Deyimden anlaşılır ki, Azerbaycan Türkleri de ne zamansa "oba"ya yardım için müracaat edermişler (Seyidov, 1994: 153).

Kanımızca, oba tabirinin dilde kullanılması meselesi, dil olgusunun kültürün bileşim kısmı gibi rol ve işlevinin göstergesidir. Şöyle ki, kültür etkeninin diğer katmanları dilin üzerinde oluşmaktadır. Bir sonraki aşamada ise dilbilimsel yapı, aynı katmanların oluşumu için invaryant (değişmeyen) tablo rolünü oynar. Başka bir deyişle, dilin yapısal öğeleri, kültür katmanlarının yapısında yinelenebilir. Bu olay, yapısal-semantik yaklaşımın önemli metodolojik postulatını oluşturur. İnanç sistemine doğru yönelen yapısal yaklaşım ise dil olgusuna verilen önemi göstermektedir. Bu durumda inanç olgusu bir dil veya semiyotik gösterge bütünü gibi ortaya çıkmaktadır.

Türk halklarının doğaya olan ilgisini, doğa olaylarıyla ilgili inançlarını ve oba/obo/oboo/obon/opa gibi ses bilgisel ifadelerini çözümlerken net olarak görülmektedir ki, oba inancı karma bir yapıya sahip olan ve tarihin çeşitli aşamalarından geçmiş inançlardandır. Oba inancının incelenmesiyle, Türk halklarının en eski, kam-şaman görüşlerine kadarki süreç içerisinde doğayla ve onun türlü olaylarıyla karşılaşmadan türeyen ilkel düşüncesi belirginleşmekte, boy veya kabilelerin ilkel toplumsal mitik görüşleri ve bu görüşlerin tipolojik benzerlikleri net duruma gelmektedir. "Oba"nın Türkiye ve Azerbaycan Türklerinin Türkçeleri dışında diğer Türk halklarının, dolayısıyla Kazak, Kırgız, Uygur, Türkmen, Tatar, Karaim, Karaçay-Malkar, Nogay, Başkurt, Tobol, Hakas, Tuva, Şor, Sagay, Koybal vs. Türkçelerinde de yaşadığı görülmektedir. 
Moğolların konuşmalarında (Kagarov, 1927: 115) ve Buryatların dilinde (Şadgaron ve Oçirov, 1909: 470) de Oba tabirinin kullanıldığı görülmektedir. Oba/obo/oboo/opa ve onun diğer ses bilgisel özelliklerinin, öncelikle mekân veya yerle ilintili olduğu dikkat çekmektedir ki, bu durum, insan topluluklarının zaman bakımından yer veya mekâna olan en eski ilgisine göre açıklanabilir. Denilebilir ki, mekân veya yer kavramı, aslında vatan anlayışının ortaya çıkmasına neden olmaktadır. Bu hususta vatan veya yurt anlayışının doğrudan mitolojik düşünceyle ilintili olduğu tespit edilebilmekte ve bu anlayışın kozmolojik düşünce çağının metinlerine önemli mitologemlerden (mitik anlatı unsurları) biri gibi yansıdığı görülmektedir. Vatan mitologemi, kozmolojik dünya modelinin semiyotik (göstergebilimsel) yapısında özel bir alanı kapsamaktadır. Özellikle Oğuz kozmogonisinde semantik bakımdan güncellik arz eden işlevsel formüllerden biri, vatan mitologemidir. "Kitab-i Dede Korkut"un devimsel ve önemli unsurlarından olan vatan mitologemi, Oğuzla ilgili mitik metinlere yansımış kozmosun işlevselliğini belirleyen yapısal mekanizmanın kendisi olmakla, sonradan söz konusu Oğuz eposuna aktarılmıştır. Bu bakımdan aşağıda da üzerinde duracağımız vatan mitologemi, Oğuz eposunun sentagmatik ve paradigmatik yapısında onarılabilir.

Oba tabiri, Mahmut Kaşgarlı'nın "Divan-ü Lügatit-Türk" eserinde soy ve kabile anlamlarında geçmektedir (Kaşgarlı, 1985: 86). "Kitab-i Dede Korkut"ta ise bu tabirin göçebe toplum anlamında kullanıldığı görülmektedir: "Meger bir gün köprüsünün yamacında bir bölük oba konmışıdı. Ol obada bir yahşı hob yigit sayru düşmişidi" (Gökyay, 2006: 111). Vasili Vasilyeviç Radlov, oba tabirinin Azerbaycan, Özbek, Türkmen, Kazak, Karaim, Kırgız, Nogay, Şor, Sagay ve başka Türk lehçelerindeki anlamlarına ilişkin şöyle yazmaktadır: "Tatarlarda, Uygurlarda, eski Özbeklerde (Çağatay) "oba”, kalın kumaş çadıra ve bu çadırlarda oturanlara denilir. "Oba” Kırgız, Sagay vb. Türk halklarının dillerinde taşlardan oluşmuş küme, taş yığını (kuça), dökme kurgan ve tepe anlamlarında kullanılır. Sagaylar mezar taşına da "oba" derler" (Radlov, 1898: 1157). Taş yığını sayesinde mezar oluşturma geleneğine dair Battulga Tsend'in fikirleri de dikkat çekmektedir: "Herhangi bir dağ ya da tepenin yüksek bir noktasında çok sayıda taş yığılmasıyla mezar oluşturma geleneği, eski dönemlere ait bir gelenek olarak bilinmektedir. Örneğin, Moğolistan'da Tarnın Nehri kenarında taş yığını şeklinde oluşturulmuş büyük kurgan ve insan figürlü taş bulunan kompleks yapı ile Şiveet Ulaan olarak adlandırılan ve bahsi geçtiği şekilde taş yığınından oluşturulmuş büyük kurgan ile birlikte dişi ve erkek aslan, koç, koyun ve kuzu heykelleri ile birlikte büyük bir damgalı anıtın bulunduğu kompleks yapı, bu geleneği işaret eden önemli kalıntılardan bazılarıdır:" (Tsend, 2016: 70). Kaynaklarda geçen ve araştırmacıların söz ettiği "oba"nın şecere, topluluk, taş yığını, toprak, kurgan, mezar taşı, çadır vs. anlamları kapsadığı görülmekle birlikte, dikkat çeken önemli hususlardan biri "Kitab-i Dede Korkut"ta geçen "bir bölük oba"nın, aslında vatan veya yurt anlayışıyla aynı konuma getirilmesi meselesidir. Ayrıca 
"oba"nın toprak ve tepe gibi tanımlanması, kozmogonik başlangıçlardan biri olarak bilinen toprağın fonksiyonel özellikleri üzerinde de durulmasını gerektirir.

Türk dünyası halk edebiyatı alanında "vatan" mitologeminin semiyotik yapısı, ilk mitolojik katmanlarla ilgili olan bir olgudur. Bu katmanlardan biri topraktır. Suyun kile ve kilin toprağa dönüşmesiyle kozmogonik sürecin önemli bir aşaması oluşabilir. Toprak üzerinde bitki ve hayvanların ortaya çıkması ve yine topraktan insanın meydana gelmesi olayı, kozmogonik sürecin son aşaması olarak görülmektedir. İște söz konusu toprak-mekân olgusu, sözlü kültürde yurt-vatan olgusunun kutsallık arz etmesine neden olmakta ve toprak-yurt-vatan semantik çizgisini oluşturmaktadır.

\section{Oba İnancının Türk Dünyası Mitolojik Düşüncesi ile "Kitab-i Dede Korkut"taki Yeri}

Oba tabirinin Türk halkları arasındaki adlandırılışı veya ses bilgisel varyantları incelenirken, bu tabirin çok çeşitli anlamlarının Türk mitolojisinin eski katmanlarındaki olgulara doğru yön belirlediği görülmektedir. Bu bakımdan eski Türk kabilelerinin çevreye, yaratıcıya ve doğa olaylarına yönelik görüşleri ele alınırken ve hatta bu görüşlerin gerçeklikle denkleşmeyen boyutlarına önem verilirken Oba inancının insan ve doğa ilişkilerindeki rolü ve işlevi tespit edilebilmektedir.

Öncelikle Oba inancının hangi mitsel kavram veya anlayışıyla ilgili olduğunu belirlemek gerekir. Araştırmalara dayanarak söylemek mümkündür ki, Oba inancı özellikle yer ve dağla (taşla) ilgilidir. Vasili İvanoviç Verbitskiy, Altaylı halkların eski bir efsane metnine dayanarak şu bilgileri aktarmaktadır: "Altay dağları kendi büyüklüğü ve dış görünüşüne göre çok güzeldir; onlar tufana kadar bahadırlar, yiğitler imiş. Bu yiğitlerin bazısı velilerinin ve diğerlerinin büyüsü dolayısıyla dağa dönüşmüşler. Tufan sonrası toprak, önceki şeklini almış ve yiğitleri kendi üzerinde bulunduramaz duruma gelmiştir. Bu açıdan onların hepsi dağa dönüşür. Onların ruhu "dağın sahibi" ve "dağ ruhu" adıyla dağlarda yaşar." (Verbitskiy, 1884: 120). Aktarılan bu bilgideki dağ olgusu, insanların düşüncesinde kutsallık kazanmış varlık niteliğinde idi. Bu durumda Altay dağlarının yerle göğün kavşağında bulunduğu düşünülmektedir. Genel olarak Tanrı Ülgen karakteri, eski Türk düşüncesine altın dağda ve doğrudan gökyüzünün orta yerinde oturmuş vaziyette yansımaktadır. Aynı zamanda direk de, çadır şeklinde düşünülen mitik dünya modelinde önemli bir işlevi yerine getirmekteydi. Özellikle kamlar, gökyüzünün orta yerinde kutup yıldızının bulunup ışınlandığına ve direk gibi Gök çadırının dikey duruşunu sağladığına inanmaktaydılar. Söz konusu direk, çeşitli Türk kabileleri tarafından farklı biçimlerde (Gökyüzünün çivisi, Çivi yıldızı vs.) adlandırılmaktaydı. Dünyanın bu tür mitik modeline inanan Buryat, Tatar, Kalmuk, Başkurt, Kırgız ve Koryakların düşüncesinde yerkürenin sütunlar 
(direkler) üzerinde bulunan evle (otağ ve çadırla) karşılaştırıldığı bilinmektedir. Adı geçen Türk toplulukları, pek çok durumda tüm evreni ve dünyayı yukarısı dairesel olan çadıra benzetirlerdi. Böyle bir çadırın yukarı kısmı gökyüzünü, alt bölümü ise yerküreyi sembolize etmektedir. Dikkat çeken diğer husus şudur ki, yukarıda araştırmacının aktardığı bilgideki inanç olguları ("dağın sahibi", "dağ ruhu"), zaman geçtikçe oba kültünden kopmakta ve bir takım yeni inançlar ona eklenerek temel parçalara dönüşebilmektedirler. "Oba"dan kopan bazı olgular, daha sonra onunla ilgili gerçekleşen oyun ve ayinlerde çeşitli şekillerde yeniden ortaya çıkmakta veya ilk inanç sisteminin göstergeleri gibi yer almaktadırlar.

Leonid Pavloviç Potapov, bir takım Türk halklarında su ile dağ ruhuna yönelik inancın aynı düzeyde olduğunu belirleyip şöyle bir tespit ortaya koymaktadır: "Şorlar su ile dağ ruhuna adanmış ortak bir ayin yapar, onların anısına ortaklaşa bir kurban sunar ve söz konusu ayini doğrudan kayın ağacının altında gerçekleștirirlerdi" (Potapov, 1946: 149). “Oba”lara yönelik yapılan alan araștırmalarına dayanarak söylemek mümkündür ki, taş kümeler ("oba"lar) özellikle dağ geçitlerinde yapılmaktaydı. Vera Pavlovna Dyakonova, bu tür taş kümelerin oluşumuna dair şöyle yazmaktadır: "Yer sahibinin şerefine, yani geçitte taştan ve küçük dallardan yapılmış obaa'nın yanında her yolcu elbette durur ve geçidin sahibinin şerefine taş kümesine taş ve dal atar. Bu tür "obaa"lar ya dağ başında ya da onun yanında bulunurdu" (Dyakonova, 1977: 185). Dyakonova'nın aktardığı fikirlere paralel olarak Andrey Viktoroviç Anohin'in argümanları üzerinde de durulabilir. Anohin'e göre, Altaylılar dağ ruhunun, dağ sahibinin (tuezzi'nin) şerefine obaya taş ve dal bırakır, bez (çalama) ve at tüyü bağlarlardı (Anohin, 1924: 147). Görülmektedir ki, Altaylıların "oba" ya ilişkin yerine getirdikleri ayin ve merasimler, diğer Türk topluluklarında, örneğin Oğuzlarda farklı olgularla gerçekleşmekteydi. Özellikle Oğuz Türkleri, merasim ve ritüellerini çadır ve otağ ortamında gerçekleştirmekte ve "oba"yı sembolize eden herhangi bir dal, bez ve tüy bağlama ayinleri icra etmemekteydiler. Aynı zamanda, Altay Türklerinin inanç sisteminde dünyayı sembolize eden çadırların bütün zaman dilimlerinde beyaz renkle işaretlenmesi olayı varken, Oğuz Türklerinin inanç sisteminde rengarenk çadırların yer aldığı görülmektedir. Kanımızı "Kitab-i Dede Korkut"ta bulunan örneklerle destekleyebiliriz. Örneğin, eposta Banı Çiçek "gök çayırun" üzerindeki kırmızı otağda (Gökyay, 2006: 63), Sarı donlu Selcan Hatun ise sarı köşkte oturmaktadır (Gökyay, 2006: 125). Bu veriler dışında, aktarılan bilgiler de göstermektedir ki, yllın belirli mevsimlerinde Altay Türklerinin yerleşim yerinde, yukarıda bahsi geçen geçitlerdeki obalarda oyun, ayin ve törenler gerçekleşmekteydi. Bir takım Türk topluluklarında ise dağ ruhu sahibinin şerefine yapılan oyunlarda yer sahibi ve ruhu anılmaktaydı.

Feliks Yakovleviç Kon'a göre, Türk topluluklarından Soyotlarla Tuvinlerde ve bir takım diğer Türk halklarında dağ başında, ırmak kenarında ve geçitlerde bulunan obalarda kamlar (şamanlar) yer sahibinin 
şerefine oyun icra etmekteydiler (Kon, 1936: 37). Aktarllan bu bilgide, kamların gerçekleştirdiği ayin ve merasimlerin oyun niteliğinde olduğuna dair ciddi bir husus bulunmaktadır. Bu hususta oyun olgusunun doğada bulunan ve aniden ortaya çıkan yapılarla eşleşebilme özelliği görülmektedir. $\mathrm{Bu}$ açıdan ilkel insanın günlük yaşamı da onun dünya modeline tamamen uygundu ve insanla onun kutsal dünyası arasında her türlü ilişkiler, doğrudan törenler (ayin, merasim ve ritüeller) aracılığıyla gerçekleşmekteydi. Bilimsel araştırmalardan bellidir ki, arkaik destanların temel kaynaklarından biri kozmogonik mitlerdir ve çeşitli törensel (ritüelistik) metinler, kimi zaman arkaik destanların malzemesini de oluşturmaktadır. Söz konusu ayin nitelikli oyun ise, zaman zaman ritüelden kaynaklanan kutsallığını kaybetmekte ve eğlence nitelikli oyuna dönüşmektedir. Bu anlamda oyunlar, bütün durumlarda ritüelistik nitelikte gerçekleşmekte, başka bir deyişle, ritüel-mitolojik ritim olguları gibi değer kazanmaktadır.

V. P. Dyakonova, bahsedilen oyunlarda mal-davarın artışı ve hastalıkların olmamasına dair istekte bulunulduğuna dikkat çekmekle yanı sıra böyle bir isteğin halkın maișeti ve hayat tarzıyla ilgili olduğunu kaydetmektedir (Dyakonova, 1977: 190). Yine V. P. Dyakonova, oba (obaa)'da söz konusu amaçla yapılan oyunlarda kurbanlık hayvanın obanın önüne getirildiğini, daha sonra hoş kokulu bir bitkinin yakıldığını ve kurbanlık hayvanın üç kez obanın etrafında dolaştırılarak ağzına kutsal pınarın (arjanın) suyundan döküldügünü yazmaktadır (Dyakonova, 1977: 191). Görülmektedir ki, Oba kültüne yönelik bağımsız ayin ve oyunların gerçekleşmesi hususunda herhangi bir sınır konulmamaktaydı. Obada bulunan insanlar günlük sorunlarıyla ilgili kutsallık arz eden yerlerde (ağaç gölgesinde, ocak ve pınar başında) istedikleri zaman kurban sunabilir, dualar edebilir ve başka türlü ayinler gerçekleştirebilirlerdi.

Abdülkadir İnan'ın Oba inancını kült olarak tanımladığı ve V. V. Radlov'un yukarıda verdiği bilgilerle örtüşen fikirler aktardığı görülmektedir: "Etnografya araştırmalarından anlaşıldığına göre Şamanist Türk ve Moğol boylarında oba kültü denilen bir kült çok yaygındır. Oba steplerde toprak, dağ geçitlerinde taş yığınlarından meydana getirilen suni tepeler (höyükler)dir. Bu obalar steplerde mukaddes dağ ve tepe yerini tutarlar. Urenha'lar ibadet için yaptıkları çadır ve alaçıklara dahi "oba" derler ki bunlara göre oba tapınak (mabet) demek oluyor." (İnan, 1986: 59). A. İnan'ın aktardığı bu bilgideki "çadır" tabiri ve ayrıca "Oba" kültüyle eşleştirilebilen "otağ" olgusu, bir ev niteliğinde Oğuz eposu "Kitab-i Dede Korkut"ta geçmekte ve bu ifadeler daha net bir şekilde Oba inancını tanımlayabilmektedir: "Kazan gök alan görklü çemene çadır dikdürdü, otağın kurdu" (Gökyay, 2006: 193). Görüldüğü gibi, eposun sonuncu boyunda geçen "çadır" tabiri, doğrudan gökyüzüyle ilişkilendirilmiştir. Bu hususta Salur Kazan'ın zafer sonrası diktirmiş olduğu çadır, aslında Gök 
Tanrı anısına gök kubbe altında yapılan ve mitik dünya modelini sembolize eden bir olgudur.

Bazı kültür odaklı araştırmalar sonucu elde edilen önemli verilerde de gökyüzüyle çadır arasındaki ilişkiden söz edilmektedir. Viktor Yakovleviç Butanayev, söz konusu hususa dair şöyle yazmaktadır: "Evle sadece doğanın bazı unsurları karşılaştırılmamakta, aksine kâinat bir bütün olarak evle karşılaştırılmaktadır. Hakasların kozmolojik inançlarına göre gökyüzü, çadırın kubbesine benzerdir. Gökyüzünün duman boşluğu, başka dünyaya geçiş sayılan gökyüzünün mitolojik merkezi Kutup Yıldızıdır" (Lvova vd., 2013: 75). "Kitab-i Dede Korkut" eposunun pek çok boyu da çadır ve evlerin yapılandırılmasına ilişkin betimlemeyle başlar ve dinsel inanç gereği bir başka topluluk evlerinin yıkılıp yeni Tanrı evlerinin dikilmesiyle sonuçlanır. Bu durumun, pek çok metinlerde eski yapılara uygun bir şekilde korunup saklandığı ve bazen de dönemin isteklerine cevap verebilir biçime getirildiği görülmektedir. Önemli olan husus ise, üzerinde durulan epos metninde Türk mitik dünya modelinin bütün göstergelerinin bulunduğunu belli eden söylevlerin yer almasıdır. Eposun ilk boyunda geçen "otağ" olgusu, doğrudan mitik dünya modelinin izi niteliğindedir. Söz konusu boyda, Bayındur Hana mal edilen "Bir yere ağ otağ, bir yere kızll otağ, bir yere kara otağ kurdurmışıdı. Kimün ki oğlu kızı yok kara otağa kondurun, kara keçe altına döşen, kara koyun yahnısından önüne getürün, yerise yesün, yemez ise dursun gitsün, demişidi. Oğlu olanı ağ otağa ve kızı olanı kızıl otağa kondurun. Oğlu kızı olmayanı Allah Taala kargayupdur, biz dahı kargaruz bellü bilsün, demişidi" (Gökyay, 2006: 25) şeklinde emrivaki bir söylev yer almaktadır. Otağda veya otağlarda gerçekleşen yeme-içme merasimleri, mitik dünya modeline yönelik ritüeller idi. Bu açıdan denilebilir ki, Oğuz kozmogonik dünya modeli yapısının dikkat çeken en güncel kozmolojik metinlerinden biri ritüeldir. Genellikle ritüel, arkaik toplumun yaşamını kendinde modelleyen en önemli yapısal unsurlardandır. Görülmektedir ki, Bayındır Hanın düzenletmiş olduğu merasimde gerçekleșen dünya modelinin kapalı mekân-zaman bağlamı, "oba" (otağ veya çadır) olgusuyla doğrudan ilintilidir. Boyun başlangıç formülünün konusu, ritüel nitelikli olmakla birlikte merasimin semantik ve karşıt katmanları arasında bulunan karşılıklı bağlarla açıklanabilir.

Denilebilir ki, yukarıdaki söylevde geçen "otağ", dünya çadırı anlamındadır. Metinde erkek başlangıcı ağ (beyaz), kadın başlangıcı ise kızıl renkle ilişkilendirilir. Bu hususta beyaz renk, ışıklı, aydınlanmış ve ermiş anlamlarını kapsamaktadır ki, bu tür özellikler, sözlü gelenekte Gök Tanrının sıfatları olarak da bilinmekteydi. Aynı zamanda tüm renklerin beyaz renkten türeme olasılığı bulunmaktadır ve bu durumda "ağ otağ" (çadır), üst dünyanın modeli niteliğinde görülebilir. Kızıl renk ise, soy birliğini sağlayan kanı, bereketi ve toprağı nitelendirmekteydi ve bu tür sembolik unsur, orta dünyanın göstergesidir. Söylevde geçen kara (siyah) renk, sıkıntı ve kötülüğün belirtisidir. Bu durumda kara çadır, yeraltı dünyasının sembolü 
niteliğinde algılanabilir. Böylece, dünyanın çadır şeklinde algılanması gerçeğine önem vermiş olursak söylenilebilir ki, dünya katmanları arasındaki irtibat, makro kozmik düzeyde ok (ağaç, dağ, direk vs.) biçiminde, mikro kozmik düzeyde ise dünyanın merkezine aktarılan yaşam yerinin orta direği gibi düşünülmektedir. Üç katmanlı dünyayı yansıtan çadırlarda tüm nesneler görünürde çok açıtır ve her katmandaki dünyanın kendine özgü belirli izi bulunmaktadır. Bayındır Hanın düzenlediği ilk törende renklerin semantik açıdan sıralanmasıyla, aslında törende gerçekleşen Oğuz dünya modelinin tüm düşünce, inanç ve ilkeleri görülmektedir. Bu durum, doğrudan dünya modeli unsurlarının kozmik nitelikli özelliğiyle ilgilidir. $\mathrm{Bu}$ özellik, benzer bir sembolizm oluşturmaktadır. Şöyle ki, dünya modelinde aynı çizgi üzerindeki dünya elemanları birbiriyle yer değiștirebilir veya birbirini sembolize edebilir. Söz konusu renk simgeselliğinin ilk törenin dünya modelindeki semantik sırası, anlamsal göstergelerin yönü değişmeyen bütünü niteliğinde olmakta, aynı zamanda dünya modelinin durağan düzlemde bulunan diğer göstergeler sırasını da anlaşılır duruma getirmektedir.

\section{Sonuç}

$O b a$ inancl, arkaik dünya modelinde bütün üstünlükleri kendinde toplayan, soyutlanmış ve dolu olan bir inançtır. Oba, onu dolduracak olgularla gerçekleşebilir ve her zaman doludur. Oba'dan önceki aşama yaratılışa kadarki kaostur. Net olarak görülmektedir ki, yaratılışın var olduğu bir ortamda Oba'nın mevcut olması kozmosu, yok olması ise kaosu nitelendirmektedir. Mekan ve zaman gibi olgular mitolojik düşünceye birbirinin içine geçmiş durumda yansımaktadır. Bu açıdan, ilkel ve yahut arkaik düşüncenin herhangi bir şekilde bütüncül olarak betimlenmesi, yalnız "burada" tanımlanmasını değil, "burada-şimdi" tanımını da beraberinde getirmektedir. Bu durumda mekân ve zaman olguları bir araya gelip ayrılmaz bir bütünlük, yani kronotop (zaman ve mekân ortaklığı) oluşturabilmektedir.

Görülmektedir ki, sözlü ve yazılı kültür metinlerine yansımış Oba inancı, ilk yașam mekânı gibi kozmolojik sürecin önemli bir olgusu niteliğindedir. Bu olgu, mitolojik kronotopun kozmosu oluşturan kısmı gibi mitolojik dünya modelinde "biz" ve "bizim dünya" kavramlarının mekânsal yapısını oluşturmaktadır. Genel olarak Oba olgusu, başlangıç itibariyle mitten gelmekte ve bu olgunun genetik yapısını mitsel öz oluşturabilmektedir. Bu bakımdan Oba inancı ve bu inancı tanımlayan tabirler, bütün durumlarda mitsel dünya duyumuyla bağını korumaktadır.

\section{KAYNAKÇA}

Anohin, A. V. (1924). Materialı Po Şamanstvu u Altaysev. Sbornik Muzeya Antropologii i Etnografii Pri Rossiyskoy Akademii Nauk. Tom IV, 2. Leningrad: Rossiyskoy Akademii Nauk. 
Dyakonova, V. P. (1977). Religioznıe Kultı Tuvintsev. Sbornik Muzeya Antropologii i Etnografii, vıp. 33, "Pamyatniki Kulturı Narodov Sibiri i Severa" (vtoraya polovina XIX-naçalo XX veka). Leningrad: Nauka.

Eren, H - Gözaydın, N. - Parlatır, İ. - Tekin T. - Zülfikar, H. (1988). Türkçe sözlük. Ankara: Türk Dil Kurumu.

Gökyay, O. Ş. (2006). Dedem Korkudun Kitabı. İstanbul: Kabalcı.

İnan, A. (1986). Tarihte ve bugün Şamanizm - Materyaller ve araştırmalar. Ankara: Türk Tarih Kurumu.

Kagarov, E. G. (1927), Mongolskie “Obo" i İh Etnografiçeskie Paralleli, Sbornik Muzeya Antropologii i Etnografii, T. VI, Leningrad: SSSR Akademii Nauk.

Kaşgarlı Mahmut (1985). Divanü Lügat-it-Türk tercümesi. (Çev.: Besim Atalay), I. Cilt, Ankara: Türk Tarih Kurumu.

Kon, F. Y. (1936). Za Pyatdesyat Let: Ekspedisiya v Soyotiyu. Moskova: İzdatelstvo Vsesoyuz Obşestva Politkatorjan.

Lvova, E. L. - Oktyabrskaya, İ. V. - Sagalayev, A. M. - Usmanova, M. S. (2013). Güney Sibirya Türklerinin geleneksel dünya görüşleri / kâinat ve zaman - Nesneler dünyası. (Çev.: Metin Ergun), Konya: Kömen.

Potapov, L. P. (1946). Kult Gor na Altae. Sovetskaya Etnografiya, Nomer 2, C.145-160, Moskova.

Radlov, V. V. (1898). Opıt Slovarya Tyurkskih Nareçiy. Tom I, Çast II, SPb, SanktPetersburg.

Seyidov, M. (1994). Kam-Şaman ve onun kaynaklarına umumi bakış. Bakü: Gençlik.

Şadgaron, S. D. - Oçirov, B. D. (1909). İgrı i Uveseleniya Aginskih Buryat, Sbornikv Çest Semidesyatiletiya G. N. Potanina. Zap. İmp. Russk. Geograf. O-vopo Otd. Etnogr, T. XXXIV, s. 468-473. St.Petersburg.

Tsend, B. (2016). Bömbögör Yazıtı. Moğolistan'da Türk Ayak İzleri, 70-79. Ulaanbaatar: "Mönhiin Üseg".

Verbitskiy, V. İ. (1884). Slovar Altayskogo i Aladagskago Nareçiy Tyurkskago Yazıka. Kazan: Pravoslavnago Missionerskago Obşestva. 